\title{
Inherited lung cancer syndromes targeting never smokers
}

\author{
Hiromasa Yamamoto ${ }^{1}$, Yasushi Yatabe ${ }^{2}$, Shinichi Toyooka ${ }^{1}$ \\ ${ }^{1}$ Department of Thoracic, Breast and Endocrine Surgery, Okayama University Graduate School of Medicine, Dentistry and Pharmaceutical Sciences, \\ Okayama, Japan; ${ }^{2}$ Department of Pathology and Molecular Diagnostics, Aichi Cancer Center, Nagoya, Japan \\ Contributions: (I) Conception and design: All authors; (II) Administrative support: H Yamamoto, S Toyooka; (III) Provision of study materials \\ or patients: S Toyooka; (IV) Collection and assembly of data: H Yamamoto, S Toyooka; (V) Data analysis and interpretation: All authors; (VI) \\ Manuscript writing: All autehors; (VII) Final approval of manuscript: All authors. \\ Correspondence to: Shinichi Toyooka, MD, PhD. Department of Thoracic, Breast and Endocrine Surgery, Okayama University Graduate School of \\ Medicine, Dentistry and Pharmaceutical Sciences, 2-5-1 Shikata-cho, Kita-ku, Okayama 700-8558 Japan. Email: toyooka@md.okayama-u.ac.jp.
}

\begin{abstract}
Lung cancer is the leading cause of cancer death worldwide. Most of lung cancers develop sporadically and thus inherited lung cancers are rare. Several reports show that germline mutations in the kinase domain of epidermal growth factor receptor $(E G F R)$ such as R776G, R776H, T790M, V843I and P848L, predispose to develop lung cancer. Most lung cancer cases with germline EGFR T790M mutations had secondary EGFR somatic mutations. Never smokers with germline EGFR T790M mutations develop lung cancer more frequently than ever smokers. In addition, germline EGFR T790M mutations favored female gender. Therefore, germline EGFR T790M mutations result in a unique inherited lung cancer syndrome targeting never smokers. The authors previously reported a Japanese familial lung cancer pedigree with germline mutations in the transmembrane domain of human epidermal growth factor receptor 2 (HER2). The female proband and her mother in this pedigree, who were light or never smokers, developed multiple lung adenocarcinomas, and had germline HER2 G660D mutations. They had no EGFR somatic mutations or other genes known to cause lung cancers. Although we know only one pedigree with germline HER2 mutations, these mutations may also cause inherited lung cancers targeting female never smokers. Based on our in vitro analyses, we administered HER2 inhibitor afatinib to the proband and achieved partial response. These lung cancers arising from germline mutations of receptor tyrosine kinases such as EGFR and HER2 may have different features from those with sporadic mutations.
\end{abstract}

Keywords: Inherited lung cancer syndromes; epidermal growth factor receptor (EGFR); human epidermal growth factor receptor 2 (HER2)

Submitted Jan 01, 2018. Accepted for publication May 24, 2018.

doi: $10.21037 /$ tlcr.2018.06.01

View this article at: http://dx.doi.org/10.21037/tlcr.2018.06.01

\section{Introduction}

Lung cancer is one of the refractory malignancies and the leading cause of cancer death worldwide (1-3). This disease is often diagnosed at the advanced stages, in which the treatment is less effective, and thus it still has a poor outcome. To improve a worse prognosis, various researches have been conducted. One of the significant research progress is the discovery of the somatic activating mutations in the tyrosine kinase domain of epidermal growth factor receptor $(E G F R)$ (4-6). These mutations mainly consist of exon 19 deletion and exon 21 point mutation (L858R), and frequently occur in adenocarcinoma, female, East Asian, and never smokers (7). Lung cancers with EGFR activating mutations initially well respond to EGFR tyrosine kinase inhibitors (TKIs), such as gefitinib and erlotinib (4-6). EGFR-TKIs showed prolonged diseasefree survival in phase III clinical trials (8-10). However, the tumors eventually acquire the resistance to TKIs, which is the issue to be overcome. One of the major mechanisms for the acquired resistance to TKIs is a secondary EGFR mutation T790M in exon $20(11,12)$. T790M mutations 


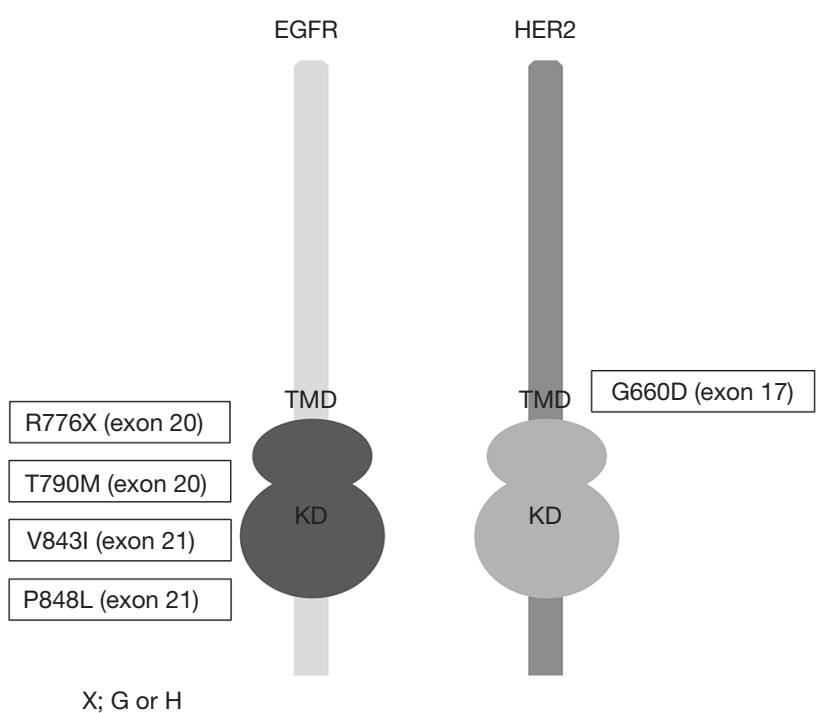

Figure 1 Schema of EGFR and HER2. Germline EGFR R776X (X; G or H), T790M, V843I and P848L mutations reported in lung cancers are located in the kinase domain. Germline HER2 G660D mutation is located in the transmembrane domain. TMD, transmembrane domain; $\mathrm{KD}$, kinase domain.

may exist in treatment-naïve tumors, and the clones with T790M are selected in the course of the TKI treatment (13). More recently, immune checkpoint inhibitors have brought change to the treatment of lung cancer and showed the promising therapeutic effect (14). In this manner, the treatment of lung cancer has been drastically changed. However, to improve the outcome of lung cancer more, it is necessary to further understand molecular oncology, and one of the approaches may be the comprehension of cancer susceptibility including inherited germline alterations.

Although vast majority of malignancies from various organs develop sporadically, we sometimes encounter inherited cancer syndromes, such as hereditary nonpolyposis colorectal cancer (HNPCC), familial adenomatous polyposis (FAP), hereditary breast and ovarian cancer syndrome (HBOC), Li-Fraumeni syndrome, retinoblastoma, and multiple endocrine neoplasia (15-20). Compared to other organs, most of lung cancers develop sporadically and inherited lung cancers are rare. While inherited lung cancers are rarely observed, several reports investigated genetic susceptibility to inherited lung cancers (21-26). Those previous reports describing inherited lung cancers did not much focus on the relationship between genetic factors and smoking status.

In this review, we introduce the reported inherited lung cancer pedigrees with germline mutations, and discuss the features of such inherited lung cancers, especially smoking status, sex, and ethnicity.

\section{Driver mutations in lung cancer}

Malignant tumors develop due to the accumulation of the mutations in a portion of genes, which provide growth advantage. Systematic resequencing of cancer genomes led to the discovery of the new cancer-related genes. While many somatic mutations are observed in cancers, most of them are likely to be "passengers", which do not contribute to carcinogenesis. On the other hand, "driver" mutations exist in a subset of somatic mutations, which are responsible to develop cancers (27). In lung cancer, several gene mutations are reported to be drivers. In addition to $E G F R$ described above, mutations of KRAS, ALK, human epidermal growth factor receptor 2 (HER2), $B R A F$, PIK3CA, AKT1, MAP2K1 and MET are reported to be drivers in lung cancer (28). These alterations are potential therapeutic targets, and molecular targeting drugs such as EGFR-TKI are developed.

\section{Previously reported inherited lung cancer pedigrees with germline EGFR mutations}

As described above, inherited lung cancers are rarely observed. However, several reports investigated genetic susceptibility to inherited lung cancers, and the reports describing EGFR germline mutations in lung cancer pedigrees draw the attention of us (29-37). In addition to these reports, lung cancer cases with germline EGFR mutations are reported, although the evident familial history of lung cancers are not obtained (38-40). Reported EGFR germline mutations are R776G, R776H, T790M, V843I and P848L, which are all located in the kinase domain of EGFR (Figure 1), and notably, T790M mutations are frequently reported $(29,31,32,34,35,37)$ (Table 1). In the pedigrees with EGFR germline mutations including T790M, many of affected family members develop secondary somatic EGFR activating mutations such as exon 19 deletion and L858R. Presumably, T790M mutation itself is a weak oncogene. However, when secondary somatic mutations occur, the oncogenic power of combined germline and somatic mutations should become enormous. Gazdar et al. studied the pedigrees with germline EGFR T790M mutations in detail. Several patients with germline T790M mutations had multiple lung tumors, and computed tomography 
Table 1 Reported lung cancers with germline RTK mutations

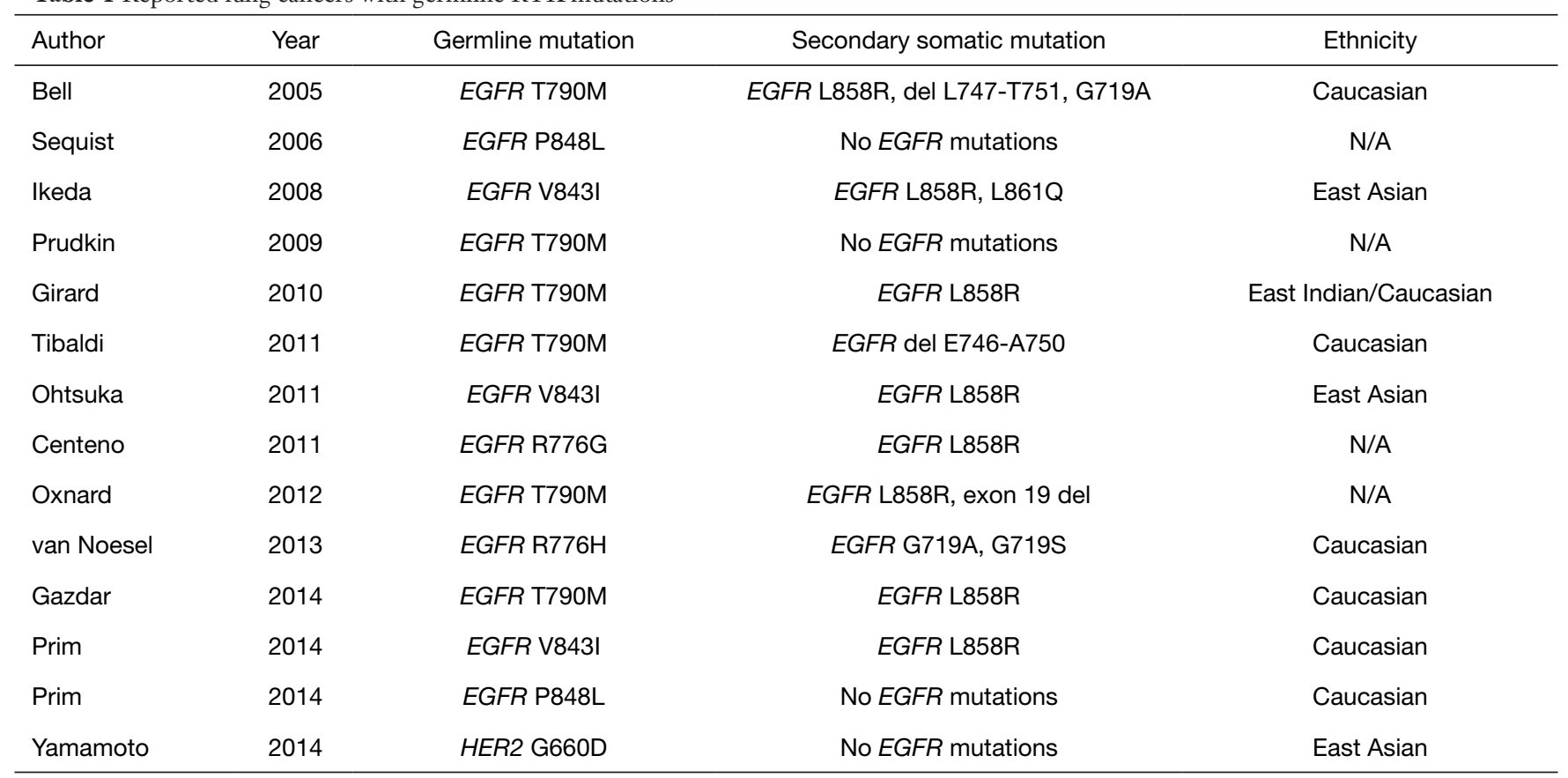

RTK, receptor tyrosine kinases; EGFR, epidermal growth factor receptor; HER2, human epidermal growth factor receptor 2.

(CT) scans of unaffected carriers revealed multiple ground glass nodules of uncertain etiology, implying that they have multiple preinvasive lesions (29). They also showed the association of sex and smoking status with developing lung cancer, indicating that germline T790M mutations targeted female never smokers, different from sporadic lung cancers, most of which target ever smokers (29). Interestingly, all the affected family members with germline T790M mutations are Caucasians or East Indians, that is, the absence of reported T790M germline mutations in East Asian ethnicity, whereas sporadic EGFR mutations mainly occur in East Asians. Reported affected members with germline EGFR V843I mutations in 2 reports are East Asians and another report shows a Caucasian (Table 1).

\section{Germline mutation of HER2 in a Japanese pedigree of inherited lung cancer}

There is a possibility for the oncogenes other than EGFR to cause inherited lung cancers. We previously reported a family of Japanese descent with inherited lung cancers, in which germline HER2 mutations were detected (41). The proband was 53-year-old female at the time of the analysis with multiple lung adenocarcinomas in the bilateral lungs. She was a light smoker with 1.2-pack-year history of smoking. In addition, normal-appearing lung parenchyma obtained from a lobectomy in the proband revealed innumerable small preinvasive lesions, implying the presence of precancerous changes throughout the lung. Her mother, who was a never smoker, also suffered from multiple lung adenocarcinomas. We performed exome sequencing using tumor and blood samples of affected and unaffected family members. Novel germline HER2 mutations G660D were detected in the transmembrane domain, although reported HER2 somatic mutations are located in the kinase domain $(42,43)$. In contrast to the lung cancers with germline EGFR mutations, we were not able to detect secondary somatic mutations of the genes known to cause lung cancers including EGFR (Table 1). We also confirmed no copy number gain of HER 2 in the examined tumors. Based on our in vitro analyses (44), we administered HER2 inhibitor afatinib to the proband and achieved partial response (45). We tested the mutational status of HER2 using the blood sample for the proband's daughter, who received the genetic counseling before testing and after the results were obtained. She also had germline HER2 G660D mutation. Her tobacco exposure was 4.5 packyears, indicating a light smoker. Computed tomography (CT) scan of the chest for her at the age of 30 is shown in Figure 2. Multiple ground-glass nodules in bilateral lungs 

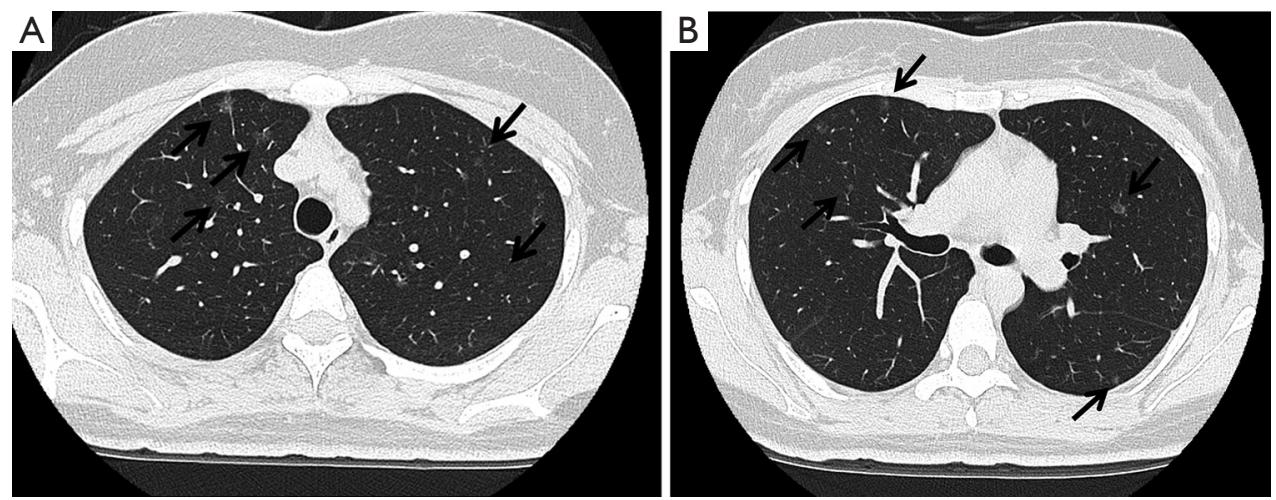

Figure 2 Computed tomography (CT) scan of the chest of the proband's daughter in the pedigree with germline HER2 G660D mutation at the age of 30. Multiple ground-glass nodules in bilateral lungs are observed.

were observed, similar to the carriers with germline EGFR T790M mutations. In this pedigree, among nine lung cancer patients, female patients are six, accounting for $66.7 \%$ (41). Although information of smoking status in this pedigree is limited to only the proband (with lung cancer), her mother (with lung cancer) and her daughter (carrier with multiple ground glass nodules), those three members are never or light smokers. Therefore, there is also the possibility that germline HER2 transmembrane mutations target female never smokers, same as germline EGFR T790M mutations.

\section{Germline mutations other than EGFR/HER2 that predispose to lung cancer}

There are several reports that describe germline mutations other than EGFR/HER2, which predispose to lung cancer. Germline mutation of BRCA-associated protein-1 (BAP1) has been associated with the high risk for malignant mesothelioma, lung adenocarcinoma, uveal melanoma, and cutaneous melanoma (46). Germline BRCA1 mutation was detected in a patient with non-small cell lung cancer who responded to cisplatin/gemcitabine plus HSP90 inhibitor DEBIO0931 (47). Rare variant BRCA2 K3326X was reported to be associated with squamous cell lung cancer (48). A familial $C D K N 2 A$ mutation R112dup has been associated with an increased risk of lung, head and neck and gastroesophageal cancer in patients who smoke (49). LKB1 is mutated in the germ-line of patients with the PeutzJeghers syndrome, which have an increased incidence of several cancers including lung cancers (50). Germline SFTP2A mutation is reported to cause familial idiopathic pulmonary fibrosis and lung cancer (51).

Next generation sequencing technology makes it possible to perform comprehensive analysis of genome in high speed. Some studies successfully narrowed down the several candidate genes $(22,52)$. While functional analysis is critical, accumulation of these knowledge will lead to identification of causative genes, which results in elucidating carcinogenesis of lung cancer as well as in developing the new therapeutic strategies of lung cancer.

\section{Single nucleotide polymorphisms (SNPs) and susceptibility of lung cancer}

Single nucleotide polymorphism (SNP) is a variation at a single position in the genome, if the frequency of the variation is more than $1 \%$ in the population. Several SNPs are reported to be associated with the susceptibility of lung cancer. Genome wide association studies (GWAS) revealed that SNPs at $15 \mathrm{q} 25$, which is the site of nicotinic acetylcholine receptor subunit genes CHRNA5, CHRNA3, CHRNB4, were strongly associated with lung cancer (53). Lan and colleagues revealed three susceptibility loci at 10q25.2 (rs7086803), 6q22.2 (rs9387478) and 6p21.32 (rs2395185) in Asian women who never smoked. They also observed that no evidence of association for lung cancer at $15 \mathrm{q} 25$ in never-smoking women in Asia (54). Wang and colleagues reported that SNPs at $5 \mathrm{p} 15.33-$ TERT (rs2736100) and 5p15.33-CLPTM1L (rs4975616) were associated with lung cancer in never smokers (55). Another GWAS study reported that 10 SNPs including newly detected two loci, 17q24.3-BPTF (rs7216064) and 6p21.3-BTNL2 (rs3817963), were associated with lung adenocarcinoma risk in never-smoking Asian women. Of these 10 SNPs, three SNP markers TERT, TP63 and 9p21.3 were also significantly associated with lung adenocarcinoma 
risk in Western never-smokers. Among Western smokers, only two out of 10 SNPs (TERT and TP63) were significantly associated with lung adenocarcinoma risk (56).

\section{Conclusions}

Germline EGFR T790M mutations cause rare and characteristic inherited lung cancer syndromes, which target female never smokers. Although only one pedigree is so far reported regarding inherited lung cancer syndrome with germline HER2 mutations, this syndrome may also target female never smokers. Because unaffected family members in these pedigrees have an increased risk to develop lung cancer, it is necessary to follow them deeply by the CT scan of the chest. Even though inherited lung cancers are rare, these molecular characteristics may be contributory to understanding the pathogenesis of lung cancer, and thus they also may shed light on the elucidation of sporadic lung cancers.

\section{Acknowledgements}

This work was supported by a Management Expenses Grants for National University Corporations in Japan.

\section{Footnote}

Conflicts of Interest: The authors have no conflicts of interest to declare.

\section{References}

1. Siegel RL, Miller KD, Jemal A. Cancer statistics, 2018. CA Cancer J Clin 2018;68:7-30.

2. Malvezzi M, Carioli G, Bertuccio P, et al. European cancer mortality predictions for the year 2017, with focus on lung cancer. Ann Oncol 2017;28:1117-23.

3. Katanoda K, Hori M, Matsuda T, et al. An updated report on the trends in cancer incidence and mortality in Japan, 1958-2013. Jpn J Clin Oncol 2015;45:390-401.

4. Pao W, Miller V, Zakowski M, et al. EGF receptor gene mutations are common in lung cancers from "never smokers" and are associated with sensitivity of tumors to gefitinib and erlotinib. Proc Natl Acad Sci U S A 2004;101:13306-11.

5. Paez JG, Janne PA, Lee JC, et al. EGFR mutations in lung cancer: correlation with clinical response to gefitinib therapy. Science 2004;304:1497-500.
6. Lynch TJ, Bell DW, Sordella R, et al. Activating mutations in the epidermal growth factor receptor underlying responsiveness of non-small-cell lung cancer to gefitinib. N Engl J Med 2004;350:2129-39.

7. Shigematsu H, Lin L, Takahashi T, et al. Clinical and biological features associated with epidermal growth factor receptor gene mutations in lung cancers. J Natl Cancer Inst 2005;97:339-46.

8. Maemondo M, Inoue A, Kobayashi K, et al. Gefitinib or chemotherapy for non-small-cell lung cancer with mutated EGFR. N Engl J Med 2010;362:2380-8.

9. Mok TS, Wu YL, Thongprasert S, et al. Gefitinib or carboplatin-paclitaxel in pulmonary adenocarcinoma. $\mathrm{N}$ Engl J Med 2009;361:947-57.

10. Mitsudomi T, Morita S, Yatabe Y, et al. Gefitinib versus cisplatin plus docetaxel in patients with non-small-cell lung cancer harbouring mutations of the epidermal growth factor receptor (WJTOG3405): an open label, randomised phase 3 trial. Lancet Oncol 2010;11:121-8.

11. Kobayashi S, Boggon TJ, Dayaram T, et al. EGFR mutation and resistance of non-small-cell lung cancer to gefitinib. N Engl J Med 2005;352:786-92.

12. Pao W, Miller VA, Politi KA, et al. Acquired resistance of lung adenocarcinomas to gefitinib or erlotinib is associated with a second mutation in the EGFR kinase domain. PLoS Med 2005;2:e73.

13. Inukai $M$, Toyooka $S$, Ito $S$, et al. Presence of epidermal growth factor receptor gene T790M mutation as a minor clone in non-small cell lung cancer. Cancer Res 2006;66:7854-8.

14. McCall NS, Dicker AP, Lu B. Beyond Concurrent Chemoradiation: The Emerging Role of PD-1/PD-L1 Inhibitors in Stage III Lung Cancer. Clin Cancer Res 2018;24:1271-6.

15. Yamauchi H, Takei J. Management of hereditary breast and ovarian cancer. Int J Clin Oncol 2018;23:45-51.

16. Pacheco MC. Multiple Endocrine Neoplasia: A Genetically Diverse Group of Familial Tumor Syndromes. J Pediatr Genet 2016;5:89-97.

17. Dimaras H, Corson TW, Cobrinik D, et al. Retinoblastoma. Nat Rev Dis Primers 2015;1:15021.

18. Galiatsatos P, Foulkes WD. Familial adenomatous polyposis. Am J Gastroenterol 2006;101:385-98.

19. Lynch HT and de la Chapelle A. Genetic susceptibility to non-polyposis colorectal cancer. J Med Genet 1999;36:801-18.

20. Li FP, Fraumeni JF Jr. Soft-tissue sarcomas, breast cancer, and other neoplasms. A familial syndrome? Ann Intern 
Med 1969;71:747-52.

21. Wilson IM, Vucic EA, Enfield KS, et al. EYA4 is inactivated biallelically at a high frequency in sporadic lung cancer and is associated with familial lung cancer risk. Oncogene 2014;33:4464-73.

22. Kanwal M, Ding XJ, Ma ZH, et al. Characterization of germline mutations in familial lung cancer from the Chinese population. Gene 2018;641:94-104.

23. Liu P, Vikis HG, Lu Y, et al. Cumulative effect of multiple loci on genetic susceptibility to familial lung cancer. Cancer Epidemiol Biomarkers Prev 2010;19:517-24.

24. Xiong D, Wang Y, Kupert E, et al. A recurrent mutation in PARK2 is associated with familial lung cancer. Am J Hum Genet 2015;96:301-8.

25. Hsu KH, Tseng JS, Wang CL, et al. Higher frequency but random distribution of EGFR mutation subtypes in familial lung cancer patients. Oncotarget 2016;7:53299-308.

26. Parry EM, Gable DL, Stanley SE, et al. Germline Mutations in DNA Repair Genes in Lung Adenocarcinoma. J Thorac Oncol 2017;12:1673-8.

27. Greenman C, Stephens P, Smith R, et al. Patterns of somatic mutation in human cancer genomes. Nature 2007;446:153-8.

28. Pao W, Girard N. New driver mutations in non-small-cell lung cancer. Lancet Oncol 2011;12:175-80.

29. Gazdar A, Robinson L, Oliver D, et al. Hereditary lung cancer syndrome targets never smokers with germline EGFR gene T790M mutations. J Thorac Oncol 2014;9:456-63.

30. van Noesel J, van der Ven WH, van Os TA, et al. Activating germline $\mathrm{R} 776 \mathrm{H}$ mutation in the epidermal growth factor receptor associated with lung cancer with squamous differentiation. J Clin Oncol 2013;31:e161-4.

31. Oxnard GR, Miller VA, Robson ME, et al. Screening for germline EGFR T790M mutations through lung cancer genotyping. J Thorac Oncol 2012;7:1049-52.

32. Tibaldi C, Giovannetti E, Vasile E, et al. Inherited germline T790M mutation and somatic epidermal growth factor receptor mutations in non-small cell lung cancer patients. J Thorac Oncol 2011;6:395-6.

33. Ohtsuka K, Ohnishi H, Kurai D, et al. Familial lung adenocarcinoma caused by the EGFR V843I germ-line mutation. J Clin Oncol 2011;29:e191-2.

34. Girard N, Lou E, Azzoli CG, et al. Analysis of genetic variants in never-smokers with lung cancer facilitated by an Internet-based blood collection protocol: a preliminary report. Clin Cancer Res 2010;16:755-63.

35. Prudkin L, Tang X, Wistuba II. Germ-line and somatic presentations of the EGFR T790M mutation in lung cancer. J Thorac Oncol 2009;4:139-41.

36. Ikeda K, Nomori H, Mori T, et al. Novel germline mutation: EGFR V843I in patient with multiple lung adenocarcinomas and family members with lung cancer. Ann Thorac Surg 2008;85:1430-2.

37. Bell DW, Gore I, Okimoto RA, et al. Inherited susceptibility to lung cancer may be associated with the T790M drug resistance mutation in EGFR. Nat Genet 2005;37:1315-6.

38. Sequist LV, Joshi VA, Janne PA, et al. Epidermal growth factor receptor mutation testing in the care of lung cancer patients. Clin Cancer Res 2006;12:4403s-8s.

39. Centeno I, Blay P, Santamaria I, et al. Germ-line mutations in epidermal growth factor receptor (EGFR) are rare but may contribute to oncogenesis: a novel germ-line mutation in EGFR detected in a patient with lung adenocarcinoma. BMC Cancer 2011;11:172.

40. Prim N, Legrain M, Guerin E, et al. Germ-line exon 21 EGFR mutations, V843I and P848L, in nonsmall cell lung cancer patients. Eur Respir Rev 2014;23:390-2.

41. Yamamoto H, Higasa K, Sakaguchi M, et al. Novel Germline Mutation in the Transmembrane Domain of HER2 in Familial Lung Adenocarcinomas. J Natl Cancer Inst 2014;106:djt338.

42. Shigematsu H, Takahashi T, Nomura M, et al. Somatic mutations of the HER2 kinase domain in lung adenocarcinomas. Cancer Res 2005;65:1642-6.

43. Stephens P, Hunter C, Bignell G, et al. Lung cancer: intragenic ERBB2 kinase mutations in tumours. Nature 2004;431:525-6.

44. Suzawa K, Toyooka S, Sakaguchi M, et al. Antitumor effect of afatinib, as a human epidermal growth factor receptor 2-targeted therapy, in lung cancers harboring HER2 oncogene alterations. Cancer Sci 2016;107:45-52.

45. Yamamoto H, Toyooka S, Ninomiya T, et al. Therapeutic Potential of Afatinib for Cancers with ERBB2 (HER2) Transmembrane Domain Mutations G660D and V659E. Oncologist 2018;23:150-4.

46. Sengupta S, Weyand AC, Upadhyaya SA, et al. Clinical Implications of Real-time Integrative Sequencing in Management of Patients With Suspected Germline BAP1 Mutations. J Pediatr Hematol Oncol 2018. [Epub ahead of print].

47. Cedrés S, Felip E, Cruz C, et al. Activity of HSP90 Inhibiton in a Metastatic Lung Cancer Patient With a Germline BRCA1 Mutation. J Natl Cancer Inst 2018;110:914-7. 
48. Wang Y, McKay JD, Rafnar T, et al. Rare variants of large effect in BRCA2 and CHEK2 affect risk of lung cancer. Nat Genet 2014;46:736-41.

49. Helgadottir H, Hoiom V, Jonsson G, et al. High risk of tobacco-related cancers in CDKN2A mutation-positive melanoma families. J Med Genet 2014;51:545-52.

50. Fernandez P, Carretero J, Medina PP, et al. Distinctive gene expression of human lung adenocarcinomas carrying LKB1 mutations. Oncogene 2004;23:5084-91.

51. Wang Y, Kuan PJ, Xing C, et al. Genetic defects in surfactant protein A2 are associated with pulmonary fibrosis and lung cancer. Am J Hum Genet 2009;84:52-9.

52. Tomoshige K, Matsumoto K, Tsuchiya T, et al. Germline mutations causing familial lung cancer. J Hum Genet 2015;60:597-603.

53. Hung RJ, McKay JD, Gaborieau V, et al. A susceptibility

Cite this article as: Yamamoto H, Yatabe Y, Toyooka S. Inherited lung cancer syndromes targeting never smokers. Transl Lung Cancer Res 2018;7(4):498-504. doi: 10.21037/ tlcr.2018.06.01 locus for lung cancer maps to nicotinic acetylcholine receptor subunit genes on 15q25. Nature 2008;452:633-7.

54. Lan Q, Hsiung CA, Matsuo K, et al. Genomewide association analysis identifies new lung cancer susceptibility loci in never-smoking women in Asia. Nat Genet 2012;44:1330-5.

55. Wang Y, Broderick P, Matakidou A, et al. Role of 5p15.33 (TERT-CLPTM1L), 6p21.33 and 15q25.1 (CHRNA5CHRNA3) variation and lung cancer risk in neversmokers. Carcinogenesis 2010;31:234-8.

56. Seow WJ, Matsuo K, Hsiung CA, et al. Association between GWAS-identified lung adenocarcinoma susceptibility loci and EGFR mutations in never-smoking Asian women, and comparison with findings from Western populations. Hum Mol Genet 2017;26:454-65. 